\title{
Dynamic Modelling of High Speed Ballasted Railway Tracks: Analysis of the Behaviour
}

\author{
Inmaculada Gallego Giner \\ Associate Professor, Department of Civil and Building Engineering, (UCLM), Spain \\ Ana Rivas Alvarez \\ Associate Professor, Department of Civil and Building Engineering, (UCLM), Spain \\ Santos Sánchez-Cambronero García-Moreno \\ Associate Professor, Department of Civil and Building Engineering, (UCLM), Spain \\ Julián Lajara Camacho \\ Master Student. Civil Engineer, (UCLM), Spain
}

\begin{abstract}
The aim of the paper is to present a numerical model for a ballasted railway track that includes the dynamic effect of a moving train load and predicts the values of the vertical stiffness of the infrastructure. This model is therefore deemed to be a tool for the evaluation of the state of the track during service situations as well as a predictive model of the behaviour of the system. Consequently, it will be very useful when sizing the cross section of a new railway line is required.

The main modelling tool is the finite element method. In regard to this, the application of damping elements to avoid the elastic wave reflection on the boundaries of the numerical domain will be studied. The proposed dynamic analysis consider the change in time of the value of the train load, but not the change in position along the tracks.

In the end, a set of suggestions for the numerical model with moving loads will be summarize aiming for the mitigation of the unusual behaviour of the contact surface between the ballast and the sleepers.
\end{abstract}




\section{Introduction}

Practicing engineers require a wide range of skills in today's competitive world. Although they must be aware of the technical, environmental and economic context in which their task are held, sometimes the scale of the projects do not allow to control as many variables as it should be required. This presentation is an example of how a methodology can be implemented to help the engineers in the decision making process when facing design problems in high speed railways.

In today's economy, budgeting and project appraisal has become more and more important during the inception of a new infrastructure and during the tendering process. It is crucial to prove that the money is well expended. But when designers have not the appropriate tools, saving money become rather a hope than a fact. This example fits very well the case of the design of High Speed ballasted tracks. In Spain, the methodology for the design of this kind of railway lines have relied on the Card 719R by the UIC (Union International de Chemins de Fer, 1994). According to this, the thickness of the ballast and sub-ballast layers depend on the traffic of the line, and the quality of the materials of the subgrade. Different administrations have added their own recommendations, according to the national know-how. There have not been many discussions about whether this methodology is outdated or whether it can be improved.

The aim of the following document is to provide an idea of the research in this topic, on how numerical methods can be adopted in order to guarantee a cost effective infrastructure with tools that are currently available and have been proved right and useful by the industry. For this matter, a Finite Element Model has been built to be described in this paper.

When dealing with complex problems, with non-analytical solutions of equations, or with interactions between elements we need to rely on the outputs provided by numerical analysis. Otherwise, the amount of simplifications may lead to the study of a totally different scenario or even a wrong one. With this regards, the Finite Element Method can be a helpful tool for the railway designer or even to the administrators and managers. Just imagine the amount of money that would need to be put in experimental tests, or the nuisance of on-site testing, causing disruptions to the line and affecting eventually to the users. An initial investment for the calibration of a numerical model can be enough to characterise the whole infrastructure and have a better understanding of foreseeable problems.

The basic advantage that derives from the use of a model is that it allows the parametrisation of the basic geometry and properties. Therefore, these parameters can be changed and adapted to the different requirements of the track taking into account spatial variations, temporal effects, fatigue of the elements, etc.

The model proposed in this paper include a wide range of parameters, such as the number of sleepers of the model and the overall geometry of the substructure and superstructure.

\section{State-of-the-art in numerical modelling of railways}

The first numerical models aimed at the study of the behaviour of ballasted railway tracks were devised in the 70s and 80s. Those models were based on a multilayer infinite semi space composed by horizontal and homogeneous layers. The materials were supposed linear elastic and the contact between layers was assumed continuous.

However, this assumptions were lacking some consistency, as the geometry of the layers play an important role of the analysis, the materials does not behave linearly elastic and the contact between the layers is not perfect. Furthermore, a multilayer system approximates the behaviour of the system when the elastic modulus increase in depth and the elastic modulus are similar. Actually this is not very representative, as the elastic modulus of the steel of the rails is very different from the elastic modulus of the soil of the natural fill.

Apart from that, there is an important question to answer: is the ballast well represented by its elastic properties? The answer is no, and it is more accurate to use a discrete elements model (DEM) to represent it than assuming a continuous media like the soil. A finite element method (FEM) model can estimate the elastic behaviour of the ballast in the overall structure, but it cannot represent accurately stresses.

In railways, some of the proposed model were bidimensional, so a state of plane deformation was assumed (López (1977)). This did not work as expected, turning the researchers to analyse 3D models (Sauvage and Larible (1982); Profillidis (1983), (1987); Sahu et al (1999) and the Ministerio de Fomento (1999)). From this, the studies by Profillidis 
at the L'École Nationale des Ponts et Chaussées were integrated by the D-117 Committee of the Office of Research and and Experiments (ORE) in the UIC 719R File mentioned above.

In this century, the model developed by Gallego (2006) in his PhD Thesis took all the expertise derived from previous models and contributed to the parametrisation of the geometry and the soil properties, allowing for a better interpretation of results and to carry out a sensitivity analysis of whatever the parameter wanted to be checked, from the thickness of the layers or the slope of the shoulders to the mechanical properties of the materials.

Up to this point, most of the models were static, allowing only for dynamic consideration using dynamic amplification factors on the loads. Furthermore, the dynamic stiffness is equal to the static stiffness of the system. The objective of modelling the dynamic behaviour of the system becomes of paramount importance when designing a high speed railway infrastructure. This models have problems which were not present in the static analysis. The main of those is the propagation of wave in elastic media. A time dependent load and time analysis consider the inertial and viscous effects of the materials.

There are 3 types of ways to address the dynamic problem: (i) Complete finite elements method model analysis, as for example Hall (2003) and Al Shaer et al (2008); (ii) finite elements models with finite elements applied in the boundaries (Costa et al (2010) and Nguyen (2013)) and (iii) finite elements with boundary elements applied in the boundaries (O’Brien and Rizos (2005), Chebli et al (2008) and Romero (2009)).

The different papers that have been read so far has two types of approaches. Those that are extremely mathematical and based on equations, and those mainly empirical based on experimental models and data. This work want to sit in the middle of this two worlds. It want to provide an up-to-date tool using numerical simulation and calibrated experimentally, but without the need of building complex mathematical model. Therefore, it should be a tool accessible for professionals of railway engineering and perfect for analysis and design in general, without a very specific scope.

Table 1: Mechanical properties of the elements of the track

\begin{tabular}{|l|l|}
\hline \multicolumn{1}{|c|}{ Material } & $\mathrm{E}\left(\mathrm{N} / \mathrm{m}^{2}\right)$ \\
\hline Steel (rails) & $2.1 \times 10^{11}$ \\
\hline Baseplates & $2.952 \times 10^{8}$ \\
\hline Sleepers & $5.02 \times 10^{10}$ \\
\hline Ballast & $1.3 \times 10^{8}$ \\
\hline Sub-ballast & $1.2 \times 10^{8}$ \\
\hline Fill & $1.25 \times 10^{7}-3.0 \times 10^{9}$ \\
\hline
\end{tabular}

There are some specific issues regarding the use of the FEM to model railway tracks:

- There is a big difference between the mechanical properties of the elements. Table 1 shows some examples.

- There is a big difference in the size of the element. While the rails are just a few centimeters, the height subgrade may be around several meters. Again, we find hard to work with different orders of magnitude.

- Although the media is assumed continuous, and this assumption works well in most cases, the stresses in the ballast and sub-ballast cannot be estimated correctly using continuum mechanics, as the size distribution of the grains is restrictive.

Nevertheless, a FEM model becomes useful for determining the overall behaviour of the structure in terms of deflection, it makes the interaction between elements and layers easy to treat and understand and makes possible the application of different boundary conditions, as well as the introduction of different geometries within the same model.

\section{Description of model numeric proposed}


The model developed in Gallego (2006) and extended in Gallego et al (2009), (2011), (2012), (2013) and (2015) is the base of the analysis hereby presented. The model has been used after that in other studies to characterise the sensitivity of different parameters such as the quality and thickness of the fill and the natural fill layers in terms of deflections. This model was based on the proposed by the Spanish Ministry of Public Works with the following differences (apart from the parametrisation of the geometry):

- The slope of the shoulders of the substructure are considered in the analysis, although no boundary conditions apply in this area.

- The geometry is simplified by symmetry with respect to the axis of the alignment.

- The load is applied in stages. In the first stage only the self-weight is present. In the second stage the loads are applied. This loads are divided in different load scenarios to simulate a train passing over the rails. The load acts over 4 sleepers assuming different coefficients simulating the influence of the load in the rest of the sleepers.

The model was implemented in ANSYS ( ). ANSYS ( ) Mechanical is a finite element analysis tool for structural analysis, including linear, nonlinear and dynamic studies. ANSYS LS-DYNA combines the LS-DYNA explicit finite element program with the powerful pre and postprocessor of ANSYS () software. In order to use wisely the capabilities of the software, the LS-DYNA and the standard computation were used for the quasi-static situation and the static respectively.

A transient analysis has been used, introducing different loading situations. This involve the use of an implicit analysis and an explicit analysis with the LS-DYNA. In the implicit analysis, the stiffness matrix of the whole structure has to be inverted in order to solve for the acceleration field iteratively. This has a huge computational cost when the model becomes greater in size or for the use of contact elements. The explicit method is much more appropriate, because it is faster and it does not need the inversion of the stiffness matrix.

\subsection{Static / Dynamic}

The methodology of the group has followed a natural evolution of the model. First, a static analysis was carried out, accounting for dynamic effects using a dynamic amplification factor for the static loading conditions.

After that, a quasi-static model involves the discretisation of a time dependent load. In this case, for each time step the software needs to solve a different load case according to the variation of the load within time. But that load has not been conceded as a moving load. That is the next step to perform. A fully dynamic model in which the load varies within time but also it is able to move along the rails. This will complete the cycle of simulations in order to take into consideration all the effects of a real case situation. There is also many more issues to address. For example, the influence of the dynamic vertical stiffness in the overall behaviour of the structure. Another step would be the incorporation of an elastoplastic law for the soils while maintaining the dynamic analysis.

\section{2. $\quad$ Mesh of the model}

Although in the static model the size of the model does not play an important role, in the dynamic situation the wave propagation will affect the size of the elements, the size of the model and the time step considered in the analysis.

In order to avoid the numeric dispersion of the results, the following experimental relation have been followed:

$\frac{1}{5}<\frac{\Delta s}{\lambda}<\frac{1}{10}$

Where $\Delta \mathrm{s}$ is the distance between consecutive nodes and $\lambda$ is the wave length. To avoid an excessive number of nodes in the model, the less restrictive value was chosen (1/5). If we relate the wave length with a train of loads, we find that the separation between nodes will be influenced by the celerity of the wave in the soil and by the frequency of the load (this is the train passing over):

$\Delta s=\frac{\lambda}{5}=\frac{v T}{5}=\frac{v}{5 f}$ 
Where $v$ is the celerity of the wave and $\mathrm{f}$ is the frequency generated by a train. If we want to find the maximum allowable distance between nodes we should choose the minimum celerity of propagation (corresponding to the weaker material) with the maximum frequency (the faster the train can pass). The wave celerity can be easily derived, and is function of the mechanical properties of the material (Young's modulus and Poisson's ratio). From the two types of waves (Primary and Secondary), the most restrictive are the Secondary waves. The period of the train will allow us to derive the frequency of actuation of the load $(T=1 / f)$. Assuming a load per axis of the train, and being able to know the distance between bogies $(\mathrm{d})$ and the velocity of the train $(\mathrm{v})$, the frequency can be obtained from:

$\frac{1}{f}=\frac{d}{v}$

This allow us to find the maximum allowable $\Delta$ s between nodes.

If we measure now a distance $\mathrm{D}$ (see figure 1) in parallel to the main directions of our model from the point of application of the load, we would be able to find the dimensions of the model if we have a restriction regarding the wave propagation and most important, the wave reflection. Therefore, we must guarantee that the model is big enough to allow a wave to travel but not to reflect in the boundaries and distort the outputs of the model.

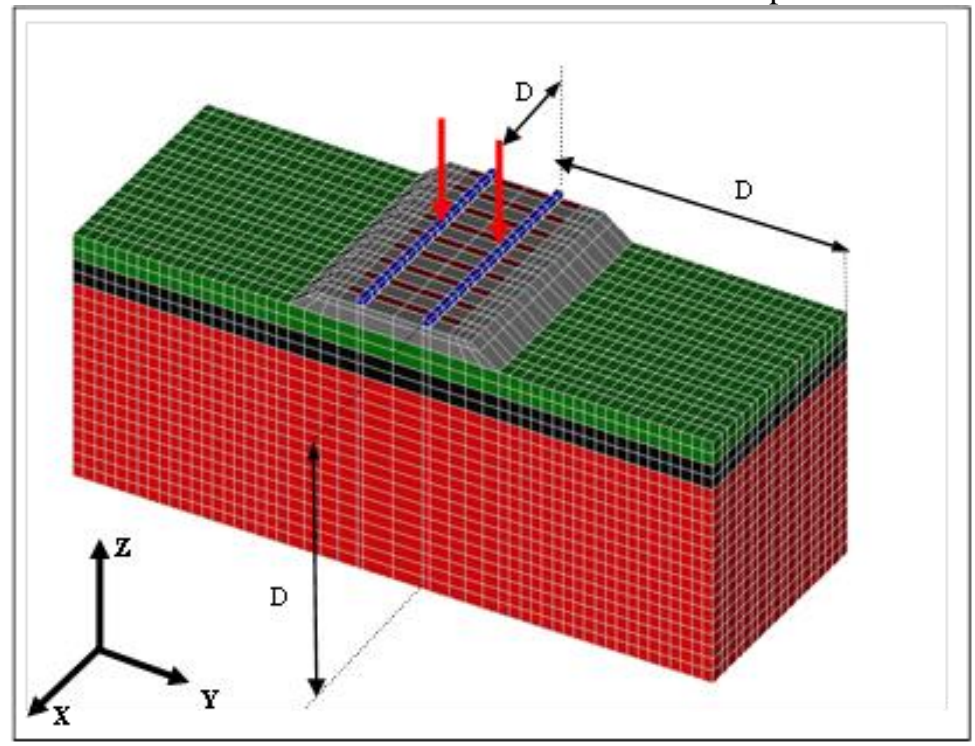

Figure 1: The proposed 3D numerical model

This condition is satisfied for any $\mathrm{D}>\mathrm{v}_{\max } / 2 \mathrm{f}_{\min }$. The maximum velocity is found in the rails, as the celerity of the Primary waves in steel is about $6140 \mathrm{~m} / \mathrm{s}$, and the minimum frequency corresponds with the minimum allowable velocity for the train. An easy calculation will give us a value of $\mathrm{D}=276 \mathrm{~m}$. This values makes the model unfeasible unless we use damping boundary elements able to absorb the wave reflection.

The elements used by ANSYS $\odot$ must change between static and dynamic analysis. For the static one, SOLID95 provides the best solution, whereas for dynamic analysis with contacts algorithm is mandatory to use the SOLID164.

\subsection{The contacts between the sleepers and the ballast}

When dealing with multilayers, the contact between surfaces need a special characterisation. In this model, the focus has to be put on the contact surface between the sleepers and the ballast. Because of the loads acting on the rails, the sleepers are subjected to high stresses, and those need to be transmitted to the ballast. It is therefore inevitable that, 
when two very different material are in contact, they behave differently. So the question is now how to accommodate the displacements and stresses of the sleepers with the displacements and stresses of the ballast. But, again, the ballast is problematic, because we are modelling it as a continuum soil. So, if the deflection of the sleeper is such that creates tension in the media below, that situation must be corrected, because it is a physical nonsense.

The numerical treatment of the interfaces of the model require a very specific treatment. The critical surface were this codes have been applied are the contact surface between the sleepers and the ballast, which are critical for the analysis.

The software ANSYS $($ allows two types of solutions: contact elements and node coupling:

- Contact Elements: it requires the duplication of the nodes of the contact surface. It introduces a fictitious layer (null thickness) between the elements. This layer has normal stiffness and a shear stiffness. Basically, it allows the separation of the nodes of the ballast and the sleepers, i.e., no physical contact. This solves the problem of finding tension stresses in the ballast. On the other hand, if a compressive stress is acting, the tangent shear moduli allow for the development of shear stresses. This friction is relevant in the problem, not only in terms of stresses, but also in terms of energy dissipation when dealing with dynamic analysis. However, this algorithm increases considerably the computational cost of the problem and incorporate new parameters to the model (the frictional law of the interfaces), which would require special characterisation and a special treatment.

- Coupling Nodes: it requires the duplication of the nodes in contact, one of the nodes is part of the upper layer and the other one is part of the bottom layer. Between opposite nodes there is kinematic constraint. This condition is applied to the "master" node, and the other, the "slave" node faces the condition imposed by the master. The normal movement with respect to the contact surface is free whereas the relative displacement between surfaces is restrained. This algorithm provides a solution for the discontinuity of stresses and displacements between sleeper and ballast without increasing the computational time. However, it does not take into account the friction between the elements and the associated dissipation of energy and it does not allow the physical separation between sleeper and ballast.

What is the best solution for modelling interfaces? According to the literature and the experience throughout the years, the separation between sleeper and ballast does occur (see Figure 2), and the friction between granular and no granular materials is relevant in the analysis, so the contact elements are needed to model correctly the track. However, the increase in computational time may become restrictive in some cases, and the determination of a frictional law between the concrete and the ballast is not obvious. As a first approach, the friction can be estimated using geotechnical criteria assuming perfect interaction between concrete and granular materials. This is assumed as $2 / 3$ of the friction angle of the ballast.

\subsection{Boundary elements}

The problem of the reflection of the waves in the boundaries can be overcome using damping elements. When modelling geomechanical systems, and infinite domain is often required to represent the ground or other larger bodies. For this type of situations, using non-reflecting elements become useful. This conditions, which the software applies automatically to the nodes, will prevent the artificial wave reflections generated at the boundary from reentering the model and contaminating the results. When this conditions are included, the algorithm computes an impedance matching functions for all the boundary segments based on an assumption of linear material behaviour. This problem can also be addressed using numerical absorbing boundary conditions based on a damped wave equations. 


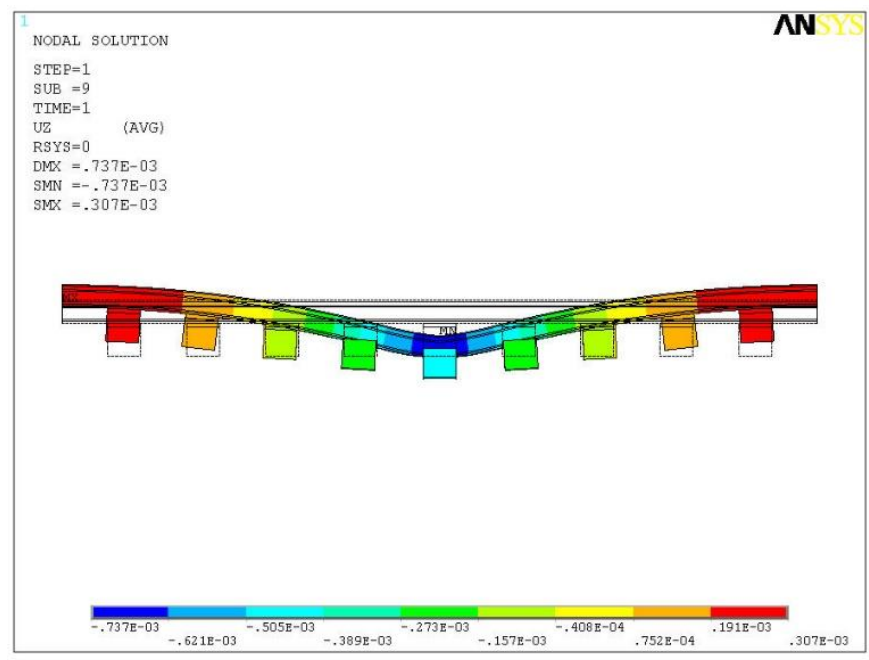

Figure 2: Deformation of the rail-plate-sleeper assembly versus the undeformed configuration

\subsection{Constitutive laws}

Initially, we can find two groups of material: rails, baseplates and sleepers plus the granular materials. The behaviour of the rails, baseplates and sleepers can be assumed as linear isotropic elastic. The rest of the materials are considered to be soils (from a modelling perspective view). Those are assumed to be controlled by a perfect elastoplastic law with a Drucker-Prager yielding surface. This is only valid for static simulations. The dynamic analysis require a linear constitutive law. Under service loads, however, a plastic analysis is not required, as the response of the railroad can be perfectly approximated using non-linear elastic constitutive laws.

\subsection{Loading conditions}

The way the load is applied need a special treatment in the problem, because depending on the way the load is input in the model we would need to change the geometry. The ultimate objective is to simulate the pass of a train over the rails, and this can be achieved in two ways:

- Triangular load: The triangular load is the easiest example of a train load. It is applied directly over the nodes of the rails, and it represents a simple axis of the bogie. The parameters of this are the maximum load and the time it takes to the load to reach that maximum. By the moment, only a time dependent load has been consider (future model will include space variability as well).

- M load: This type of load simulates the effect of a bogie with two axis following the approach defined in Sauvage (1983) (see Figure 3). It has an M shape with two peaks, corresponding to the maximum values of the load. This load is directly applied to the sleepers, so there is no need to model the rail. This may become handy, because without the rail, there is no influence of the wave propagation on the steel (which was the most limiting material), therefore it has many advantages. Among some, a smallest model. On the contrary, the function of the $\mathrm{M}$ load depends on two non-dimensional empirical variables $(\mathrm{X}$ and $\mathrm{Y})$ that are related with the elastic modulus of the soil and with the vertical stiffness of the track.

Regarding the M load, several issues have been detected. One of the most important is that the lack of rails distort the real behaviour of the tracks. The rails act eventually as a tie for the sleepers, making them connected with one another. When the M load is applied directly to the sleepers, there is no element connecting the sleepers, so there is no influence or stress distribution between them. The rail is also 
responsible for maintaining the relative position of the sleepers. This implies that we have to rely on the load function to do this work spatially. This issues affect notably the model of the structure.

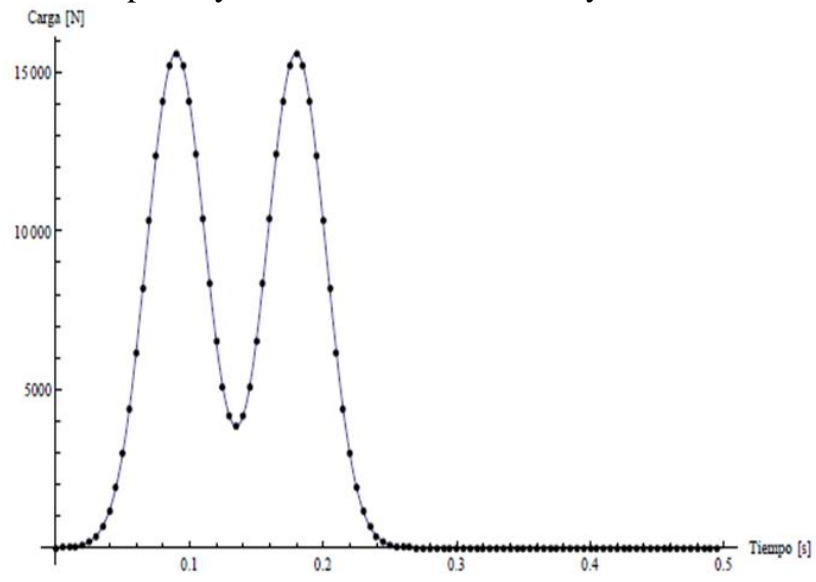

Figure 3: M load simulating the effect of a bogie with two axis (Sauvage G. (1993))

The time step is also an important parameter when deciding how to represent the load. This also represents the frequency the software is getting data to perform the calculations. There are many recommendations for the time step in the literature, but the two most recommended are the one proposed by Chopra $(\Delta t / T<0.1)$ where $\mathrm{T}$ is the period of the highest frequency and the one related to the wave celerity, which can be derive from:

$\Delta t<\frac{V}{A \cdot C}$

Where $\mathrm{V}$ is the volume of a finite element is, $\mathrm{A}$ is the area of the largest side of the finite element and $\mathrm{c}$ is the highest wave celerity in the different materials.

Apart from this, only vertical load have been considered. In railway engineering there is an important horizontal load due to the hunting movement of the train, but this out of the scope of this document.

\subsection{Computational cost}

The computational cost of the model depends on two factors:

- Size of the mesh: in previous sections we have found a relation to derive the spacing between nodes. It is recommended for the dynamic model not to have symmetry planes (because the wave reflection would be influenced by that fact). Therefore, the grater the model becomes, the number of nodes increase cubically. But if the model is not big enough, the influence of the wave reflection would cause a significant distortion of the results providing useless outputs.

- Time step: Due to the load discretisation and to guarantee the convergence criteria, the time steps need to be much reduced. This may lead to simulations of a few seconds with more than hundreds intermediate steps and calculations of the whole model.

This makes necessary to use supercomputers to solve the model, even with reduced geometries and simplifications.

\section{Conclusions}

In spite of the problems exposed in this paper, a FEM model becomes useful for determining the overall behaviour of the structure in terms of deflection, it makes the interaction between elements and layers easy to treat and understand and makes possible the application of different boundary conditions, as well as the introduction of different geometries within the same model. However, it is necessary to consider the following recommendations: 
CIT2016 - XII Congreso de Ingeniería del Transporte València, Universitat Politècnica de València, 2016. DOI: http://dx.doi.org/10.4995/CIT2016.2016.4218

- If we are dealing with a dynamic analysis, then the constitutive law of materials should be linear. One step would be the incorporation of an elastoplastic law for the soils while maintaining the dynamic analysis.

- Although in the static model the size of the model does not play an important role, in the dynamic situation the wave propagation will affect the size of the elements, the size of the model and the time step considered in the analysis.

- According to the literature and the experience throughout the years, the separation between sleeper and ballast does occur, and the friction between granular and no granular materials is relevant in the analysis, so the contact elements are needed to model correctly the track.

- The problem of the reflection of the waves in the boundaries can be overcome using damping elements, or non-reflecting elements, or one model big enough to allow a wave to travel but not to reflect in the boundaries and distort the outputs of the model.

\section{References}

Al Shaer, A., Duhamel, D., Sab, K., Forêt, G., \& Schmitt, L. (2008). Experimental settlement and dynamic behavior of a portion of ballasted railway track under high speed trains. Journal of Sound and Vibration, 316(1), 211-233.

Chebli, H., Clouteau, D., \& Schmitt, L. (2008). Dynamic response of high-speed ballasted railway tracks: 3D periodic model and in situ measurements. Soil Dynamics and Earthquake Engineering, 28(2), 118-131.

Comité D-117, Office de Recherches et d'Essais de l'Union Internationale des Chemins de Fer, 1983. Adaptation optimale de la voie classique au trafic de l'avenir. Rapport $n^{\circ}$ 27.-Comportement des structures d'assise de la voie sous charges répétées-.

Costa, P. A., Calçada, R., Cardoso, A. S., \& Bodare, A. (2010). Influence of soil non-linearity on the dynamic response of high-speed railway tracks. Soil Dynamics and Earthquake Engineering, 30(4), 221-235.

Gallego, I., \& López, A (2009). Numerical simulation of embankment-structure transition design. Proceedings of the Institution of Mechanical Engineers, Part F: Journal of Rail and Rapid Transit, 223(4), 331-343.

Gallego, I., 2006. Heterogeneidad resistente de las vías de Alta Velocidad: Transición terraplén-estructura. PhD Thesis .Universidad de Castilla La Mancha.

Gallego, I., López, A., Vieira, E. W., \& Rivas A. (2012). Design of embankment-structure transitions for railway infrastructure. In Proceedings of the Institution of Civil Engineers-Transport (Vol. 165, No. 1, pp. 27-37). Thomas Telford Ltd.

Gallego, I., Muñoz, J., Rivas, A., \& Sanchez-Cambronero, S. (2011). Vertical track stiffness as a new parameter involved in designing high-speed railway infrastructure. Journal of Transportation Engineering, 137(12), 971-979.

Gallego, I., Muñoz, J., Sánchez-Cambronero, S., \& Rivas, A. (2013). Recommendations for Numerical Rail Substructure Modeling Considering Nonlinear Elastic Behavior. Journal of Transportation Engineering, 139(8), 848-858.

Gallego, I., Sánchez-Cambronero, S., \& Rivas, A \& Laguna, E. (2016). A mixed slab-ballasted track as a means to improve the behavior of railway infrastructure. Proceedings of the Institution of Mechanical Engineers, Part F: Journal of Rail and Rapid Transit (in press).

Hall, L. (2003). Simulations and analyses of train-induced ground vibrations in finite element models. Soil Dynamics and Earthquake Engineering, 23(5), 403-413.

López, A., 1977. Análisis de la deformabilidad vertical de una vía férrea mediante el método de elementos finitos. Revista AIT nº 15.

Ministerio de Fomento, 1999. Recomendaciones para el Proyecto de Plataformas Ferroviarias. Madrid : Centro de Publicaciones del Ministerio de Fomento.

Nguyen, K., 2013. Efectos dinámicos debidos al tráfico de ferrocarril sobre la infraestructura de la vía y las estructuras. Madrid. PhD Thesis

O'Brien, J., \& Rizos, D. C. (2005). A 3D BEM-FEM methodology for simulation of high speed train induced vibrations. Soil Dynamics and Earthquake Engineering, 25(4), 289-301.

Profillidis, V., 1983. La voie et sa fondation. Modelisation mathematique. París. PhD Thesis. École Nationale des Ponts et Chaussées.

Profillidis, V., 1987. Le comportement mécanique de la traverse. Rail Internacional, pp. 25-33.

Romero, A., (2009). Modelo Numérico en el dominio del tiempo para calcular vibraciones producidas por Trenes de Alta Velocidad. Sevilla,

Escuela Técnica Superior de Ingenieros. Universidad de Sevilla, 2009. Trabajo fin de máster.

Sauvage, G. and Larible, G., 1982. La modélisation par éléments finis des couches d’assise de la voie ferrée. Revue Générale des Chemins de Fer, pp. $475-484$.

Sauvage, G., 1993. Railway track vertical static behaviour. INRETS/LTN.

Semblat, J.F. and Dangla, P., 2005. Modélisation de la propagation d'ondes et de la interaction sol-structure: aproches par éléments finis et éléments de frontière. Boulletin des Laboratoires des Ponts et Chaussées, pp. 163-178.

Shahu, J. T., Kameswara Rao, N. S. V., \& Yudhbir. (1999). Parametric study of resilient response of tracks with a sub-ballast layer. Canadian Geotechnical Journal, 36(6), 1137-1150.

Turcke, D. and Raymond, G., 1979. Three dimensional analysis of rail track structure. Transportation Research Record n ${ }^{\circ} 733$, pp. 1-6

Union International de Chemins de Fer, 1994. Ouvrages de terre et couches d'assise ferroviaries. Code 719R. 